\title{
Aerodynamic Performance Detecting for Floating Offshore Wind Turbine using RANS-BEMT Approach
}

\author{
Lin Lin \\ Department of Naval Architecture, Ocean and Marine \\ Engineering \\ University of Strathclyde \\ Glasgow, UK \\ lin.lin@strath.ac.uk
}

\author{
Dracos Vassalos \\ Department of Naval Architecture, Ocean and Marine \\ Engineering \\ University of Strathclyde \\ Glasgow, UK \\ d.vassalos@strath.ac.uk
}

\begin{abstract}
Nowadays the demands for floating offshore wind turbine (FOWT) have exceeded 5MW with the rapidly growing wind market. The aerodynamic environment of FOWT is more complex than onshore or fixed offshore wind turbine due to larger motions of the floating platform. However, a limited simulation and load estimation capability make aerodynamic analysis a challenge. It is questionable whether some industry aerodynamic analysis codes like conventional Blade Element Momentum theory (BEMT) is accurate. Results suggest that current methods for predicting the aerodynamic loads are lacking. This paper presents the unsteady aerodynamic performance of National Renewable Energy Laboratory (NREL) 5MW FOWT experiencing a periodic pitch and surge motions using commercial multi-purpose CFD solver STAT CCM+ 9.02 compared with FAST v7.0. Some discrepancies are found. 3D results are used to estimate 2D airfoil characteristics to modify two important parameters in BEMT codes: the axial and the tangential induction factors by applying the reduced axial velocity method to get the local angle of attack of CFD solutions. As shown in the results, BEMT method cannot predict aerodynamic performance accurately, especially in the motion condition. Therefore, a new modified RANS (ReynoldsAverage Navier-Stokes)-BEMT approach is raised. Corrected BEMT method using the CFD airfoil results is an interesting thing to find if it can modify the accuracy of the results
\end{abstract}

Keywords-floating offshore wind turbine, unsteady aerodynamic performance, CFD method, FAST code, RANS-BEMT approach

\section{INTRODUCTION}

As wind energy becomes the most promising renewable energy source, the study of floating offshore wind turbine (FOWT) which combined aerodynamic, hydrodynamic and mooring-system dynamic effects get more attention gradually. Wind turbine aerodynamics is exceptionally complex, and it becomes more complex for a FOWT than for an onshore or fixed offshore system. In particular, while a fixed wind turbine has a simple flow state, the FOWT experiences complex flow states when the floating platform is in motion [1]. FOWT includes three translation components (heavy in the vertical, sway in the lateral and surge in the axial) and three rotational components (yaw about the vertical axis, pitch about the lateral and roll about the axial) as shown in Fig. 1 [2].

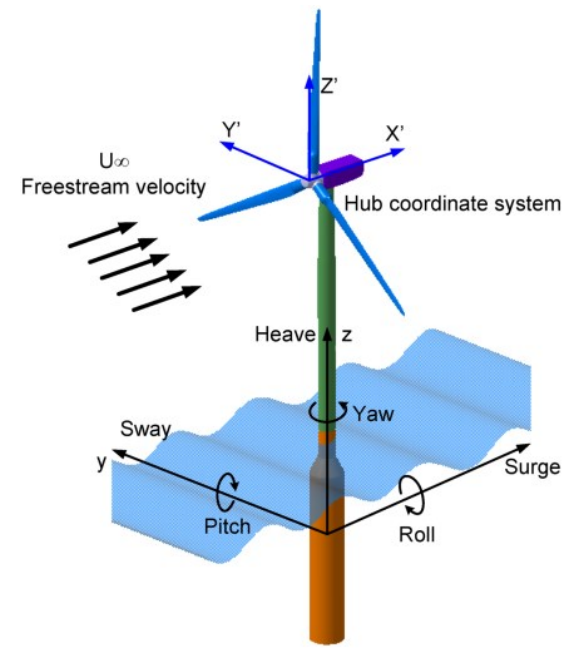

Fig. 1. Degrees of freedom for a FOWT platform and its effects on the surrounding [4]

The prediction of aerodynamic loads is fundamental to the design and simulation of wind turbine systems. A number of codes have been designed to model wind turbine behaviour. Blade Element Momentum theory (BEMT) is a very engineering model based on simple momentum and strip theory. Analysis codes used to verify the stability and the ability of a FOWT structure to withstand experienced loads (e.g. Bladed, FAST or HAWC2) all base aerodynamic calculations on the BEMT method. The classical BEMT method determines induced velocities at the rotor plane by assuming equilibrium between applied aerodynamic loads and the induced flow field. The mentioned aerodynamic effects are just trying to be realized by engineering correction models, since BEMT methods cannot model a turbulent region behind the rotor, dynamic stall condition and yawed inflow conditions.

However, these aerodynamic flow effects cannot be accurately modelled using traditional BEM theory with common corrections, as Sebastian and Lackner [7][8] have 
shown. CFD, which solves Euler of Reynold Average Navierstokes (RANS) equations, provides more physically realistic simulation. The current investigations employ an advanced transitional modelling technology coupled with the SpalartAllmaras turbulence model and an efficient sliding interface method to address both physical and numerical modelling challenges faced in the wind turbine CFD simulations. Therefore, CFD method is an appropriate choice to simulate flow separation and wake interaction, though it incurs a significant computational cost. CFD serves to study the finer details of certain scenarios which are not possible with the software like FAST.

A continuing study [5] comparing BEMT and CFD for a generic multi-megawatt rotor with prescribed FOWT pitch motion is currently conducted with a full three-dimensional CFD model of the rotor in the RANS code FLOWer (a URANS/LES (Large Eddy Simulation) CFD solver for structured meshes, developed by the German Aeronautical and Aerospace Centre DLR). The results of the National Renewable Energy Laboratory (NREL) study indicate that the current stateof-the-art in wind turbine analysis relies too much on subjective, loosely-defined parameters and too little on an accurate understanding of the physical phenomena that drive wind turbine aerodynamics. This problem needs to be further exacerbated when attempting to analyse floating horizontal axis wind turbines (HAWTs).

The capacity of standard engineering tools for the design of wind turbines to capture this complexity may be questioned. Gueydon [10] applied a common solution that consists of optimizing the load coefficients of the rotor to reproduce the measured rotor loads. Several approaches (XFOIL + FAST, RANS + FAST, Optimization with XFOIL and FAST, Optimization with FAST only) are compared. Based on these findings, two methods were proposed to expand the applicability of BEMT-based tools to off-design and model scale conditions. First, instead of using commonly used 2D XFOIL data, 2D CFD RANS data were used. The use of purely 2D data from 2D CFD RANS computations did however not result in the desired improvements when compared to XFOILbased results. The second proposed method was based on the use of 2D airfoil data obtained by post-processing of 3D flow data coming from 3D CFD computations. This new approach was shown to be successful and can therefore be extremely useful for future model scale FOWT testing campaigns to do preliminary performance predictions. A comparative study of these tools against model scale experiments showed that standard BEMT-based tools using 2D airfoil data coming from XFOIL, are not suitable for model scale performance predictions due to the large scaling [11]. Therefore instead of using XFOIL, data coming from 2D RANS computations were used. Although the RANS based results were useful in analysing 2D scaling effects its use in conjunction with BEMT did not result in improved performance predictions due to the highly $3 \mathrm{D}$ character of the flow which is not considered within the conventional BEMT [12]. However, this method was just applied in the model scale simulation.

The major objective of the present work is to show the different predictions among FAST (Fatigue, Aerodynamics, Structures, and Turbulence) code with AeroDyn module of routines developed by the NREL, CFD and RANS-BEMT approach for a FOWT. The pitch and surge complex motions of a FOWT are examined. A 3D unsteady flow is performed using the RANS equation with the shear-stress transport (SST) K- $\omega$ turbulence model. These three methods perform well for a NREL 5MW FOWT undergoing periodic pitching and surging. Differences in loads are compared and analysed and conclusions drawn concerning the applicability and limitations of each aerodynamic method for ultimate load prediction. Moreover, this paper looks at a common solution that consists of optimizing the load coefficients of the rotor to reproduce the measured rotor loads. A link between RANS and BEMT calculations is implemented. 2D and 3D RANS results are as input for BEMT computations. The BEMT results based on a 3D calculations come close to the full CFD results. Therefore, the RANS-BEMT coupled approach may be an option to be taken into account.

\section{RANS-BEMT APPROACH}

Numerous engineering tools rely on pre-calculated 2D force coefficients for the aerodynamic loads. Multiple approaches to achieve these coefficients have been proposed and often these coefficients are simply tuned to better fit the measured thrust and power delivered by the rotor. A common solution consists of optimizing the load coefficients of the rotor to reproduce the measured rotor loads. Two variants of optimizations are implemented. First, instead of using commonly used 2D airfoil data, 2D CFD RANS data were utilized. To account for this 3D character, the second proposed method is built on the use of 2D airfoil data obtained by post-processing of 3D flow data coming from 3D CFD computations. With the proposed method and a sufficiently accurate CFD computation, it is possible to obtain airfoil characteristics from a give wind turbine design without using empirical stall corrections model. How to get 2D airfoil data will be outlined in the following sessions.

Coupling method of FAST (a BEMT code of NREL for coupling of rotor aerodynamic and floater hydrodynamics) and STAR CCM+ (a commercial CFD software) is characterized as follows:

1. Start point: CFD results

- Obtaining axial and tangential forces from CFD:

- Integration of pressure and shear stress for 2D section

- Calculation of $\{\mathrm{CL}, \mathrm{CD}$ and $\alpha\}$

2. Input for FAST

- Results of FAST:

- Thrust and power coefficient (Rot RT $_{C}$ and $\left.\operatorname{Rot}_{\mathrm{CP}}\right)$

- Axial and tangential induction factors (a and a')

It is well established that the actual incidence of the flow around a wing or blade is difficult to define owing to the wakeinduced effects stemming from the vortical flow around the rotating blades. This will affect the local inflow angle. Here we will present a method of determining this local angle of attack $\alpha$. Using CFD data to obtain the annular average of the axial velocity (and thereby the induction a) at a given radial position in the rotor plane [20][21]. 
The method, which was originally proposed by Hansen [22] is a way to determine the actual inflow velocity taking into account the decrease in axial flow due to the presence of the rotor. The velocity field within an annulus of a given radial location (see Fig. 2) is obtained and averaged, and this procedure is carried out at different stream wise positions to obtain axial velocities as a function of the stream wise position.

By sweeping this annular plane from upstream to downstream of the rotor in the axial direction, the averaged axial velocity can be plotted as a function of the distance from the rotor plane, and the axial induction factor $\alpha$ can be determined by reading the axial velocity in the rotor plane (Fig. 3 ). Once the velocities are known as a set of upstream and downstream positions, its value at the rotor plane can be estimated by interpolation. Once the velocity $\mathrm{V}_{\text {axial }}$ is obtained, given the local blade twist $\theta$ and its rotational $\operatorname{speed} \Omega$, the local effective angle of attack $\alpha_{\text {eff }}$ can be calculated as: $\alpha_{e f f}=$ $\tan ^{-1}\left(\frac{V_{\text {axial }}}{r \Omega}\right)-\theta$.

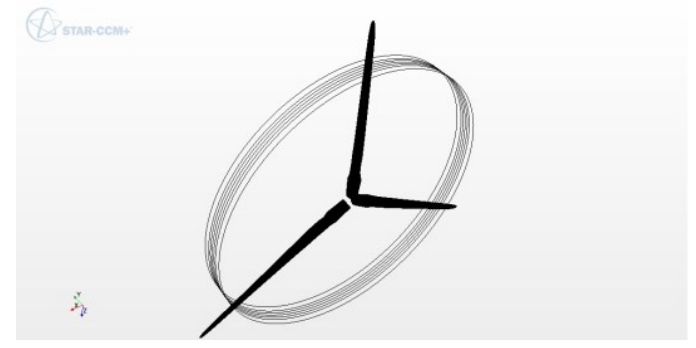

Fig. 2. the principle of the axial velocity method

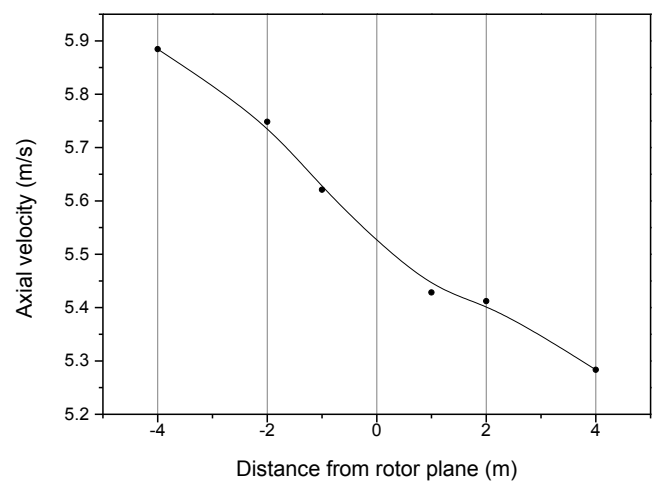

Fig. 3. the annular average of axial velocity as a function of axial distance from rotor plane, at span wise position $\mathrm{r} / \mathrm{R}=0.8, \mathrm{~V}=8 \mathrm{~m} / \mathrm{s}$

\section{CFD NUMERICAL MODELLING}

The following section will provide details of the numerical simulation approaches used in this study and will discuss the numerical methods applied to the current CFD model.

\section{A. Geometry}

The NREL 5-MW baseline wind turbine is a representative utility-scale multi-megawatt turbine suitable for floating offshore applications and all the data of the turbine are released in the public domain. This wind turbine is a conventional threebladed upwind variable-speed blade-pitch-to-feather-controlled turbine. Basic physical properties of the NREL 5MW are given by Jonkman [23]. Under the definition of a floating system of OC3 by Jonkman, a modified version of the UpWind 5MW reference wind turbine [17] on the OC3 Hywind spar buoy floating support structure has been identified.

As described above, there are six rigid-body platform DOFs including translational surge, sway, and heave motions and rotational roll, pitch, and yaw motions. Positive surge is defined along the positive $\mathrm{X}$-axis, sway is along the $\mathrm{Y}$-axis, and heave is along the Z-axis. Positive roll is defined about the positive $\mathrm{X}$ axis, pitch is about the $\mathrm{Y}$-axis, and yaw is about the $\mathrm{Z}$-axis.

\section{B. Physics modelling}

The URANS method uses a time-average formulation of the Navier-Stokes Equations to model turbulent flows in CFD. The occurring nonlinear Reynolds stress term requires the introduction of turbulence models (for example, two equation models such as $\mathrm{k}-\omega)$ to close the URANS equations. The turbulence model selected in this study is k-w SST.

A segregated flow model solves the flow equations in a segregated or uncoupled manner. All current simulations employ a semi-implicit method to solve the pressure-linked equation (SIMPLE). A finite-volume based unstructured parallelized couples algebraic multi-grid solver with a second order advection scheme. In unsteady simulation, a first-order central difference scheme is utilized to temporal discretization. To obtain the aerodynamic power and thrust of unsteady simulations of the wind turbine blade, function is adopted to extract the aerodynamic blade root load during the simulation of the pitch and surge motions of a wind turbine. A simple user field function is also created to define the simple pitch and surge of an offshore wind turbine platform. Rigid body motion is applied to define the real motion of a wind turbine blade under each specific motion using unsteady time-accurate simulations. The superimposing motions technique is implemented to define the sine function of the pitching motion of a platform.

\section{Computational Domain and Boundary Conditions}

In this research work, the blade geometry is set up in Gambit. The hub is not included in the geometry. As described above, the 5MW NREL wind turbine rotor blade has a radius of 63 meters and is composed of eight aerodynamic shapes including six airfoils and 2 cylinders with 13.3 degrees twist angle, as shown in Fig. 4.

To model a 6-DOF prescribed motion, the CFD model contains a rotating region in the immediate vicinity of the blades, and a fixed region far away from the blades. The two regions interact through a sliding boundary and the dynamic mesh capability in STAR CCM + . This is to ensure that the mesh in the rotor domain has almost no relative nodal displacement, as the mesh on the blade had first node on the order of microns to yield a $\mathrm{y}^{+}=1$, where $\mathrm{y}+$ is a non-dimensional wall distance for wall bounded flow. The hexahedral computation domain is applied to dimension of $1291 \times 504(\mathrm{~L} \times \mathrm{D})$, and extends 5.5 and 15 times the rotor radius in the negative (upstream) and positive (downstream) x-direction, respectively, see as Fig. 5. Velocity inlet and pressure outlet are applied in this simulation. 


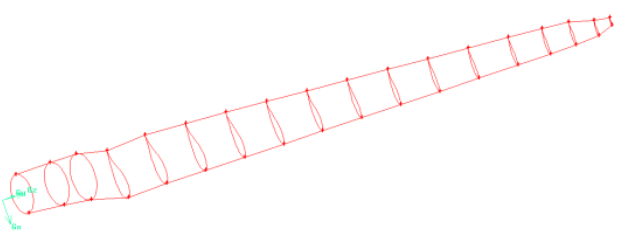

Fig. 4. Wind turbine blade shape with sketch view

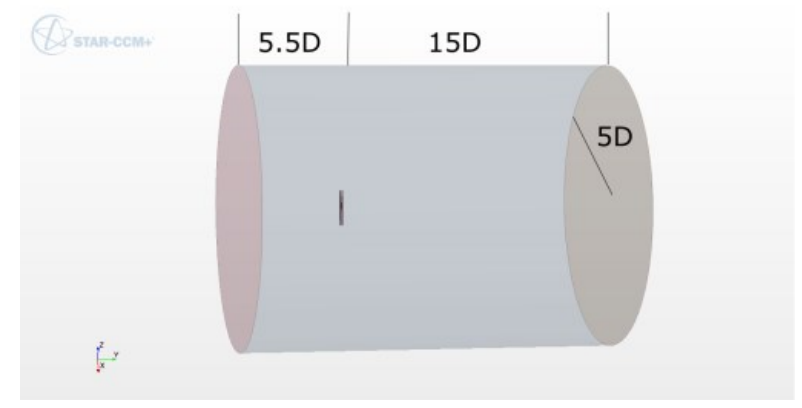

Fig. 5. Calculation domain

\section{Mesh Generation}

All regions apply prism layer, surface remesher, and trimmer mesh methods. For blade surface, a refine grid is generated at the leading edge with a maximum and minimum grid size. C-grid type mesh is created in the blade domains. Fig. 6 shows computational meshes for the upwind three-bladed turbines, which illustrate the grid density around the rotor and steady regions. The blade surface mesh resolution near the tip region is illustrated in Fig. 7.

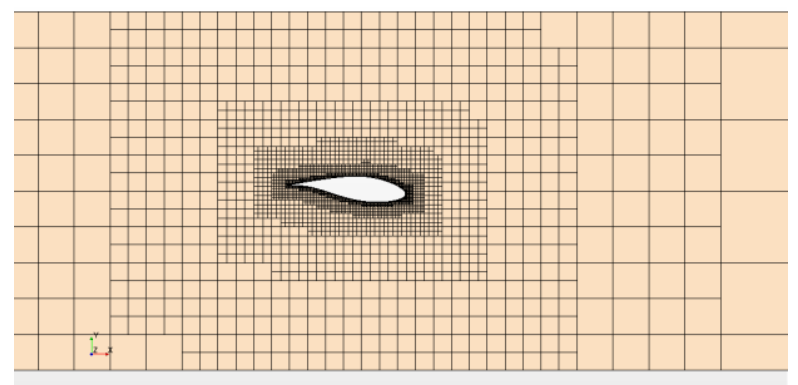

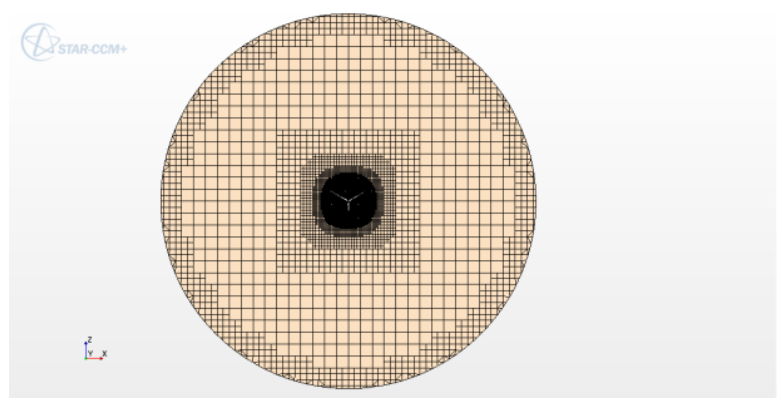

Fig. 6. Volume mesh

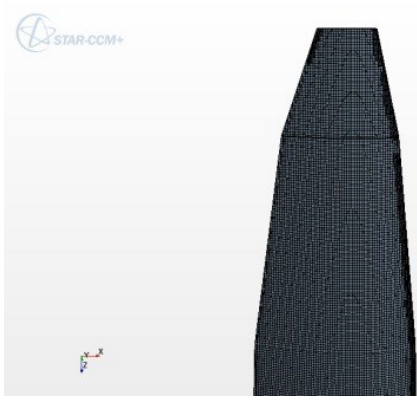

Fig.7. Blade surface grids in the tip region

\section{RESULTS AND DISCUSSION}

\section{A. CFD Grid Uncertainty Analysis}

By detecting the accuracy of the grid, three different element types are given in TABLE I to compare. In the case of wind speed $8 \mathrm{~m} / \mathrm{s}$ and rotation $9.16 \mathrm{rpm}$, Fig. 8 and Fig. 9 illustrate the aerodynamic power and thrust results over a range of elements compared within three approaches, CFD, blade element momentum (BEM) and generalized dynamic wake (GDW). The present CFD results show overall good correlations with those obtained by the FAST code.

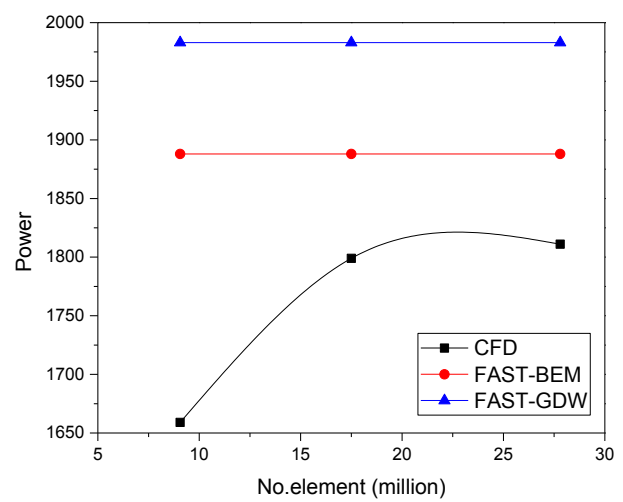

Fig. 8. Power with different elements 


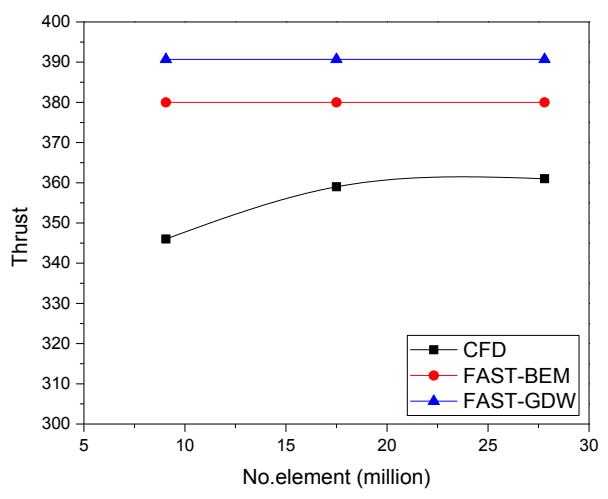

Fig. 9. Thrust with different elements

As the figures show, there are about $9 \%$ and $23 \%$ differences in the predicted aerodynamic power and thrust between the present CFD method and BEM, respectively. Nevertheless, the discrepancy between BEM and GDW is small, only $4.6 \%$ and $2.3 \%$. It is attributed to several effects will be explained later. The simulation results between case 2 and case 3 are almost the same. However, there is a big difference compared with case 1 . Flow unsteadiness of the condition of pitch and surge motion for rotating blades must be higher than that of the previous comparison case. Therefore, case 3 is chosen for the unsteady simulation in order to capture the complex wake effect behind the rotating blades.

Then a verification study is undertaken to assess the numerical simulation uncertainty, USN and numerical errors, $\delta_{\mathrm{SN}}$. There is a detailed description of uncertainty analysis in CFD verification and validation methodology and procedures in ITTC guidelines [25]. Xing and Stern [28] state that the Richardson extrapolation method is the basis for existing quantitative numerical error estimates for time-step convergence and grid-spacing. This study generates a so-called grid-triplet study Roache's [29] grid convergence (GCI) is useful for estimating uncertainties arising from grid-spacing errors. Grid-spacing convergence studies are carried out following the correlation factor (CF) and GCI methods of Stern et al. [30]. The verification parameters of power and thrust for the grid spacing convergence studies are demonstrated in TABLE II.

For the mesh convergence study, a uniform refinement ratio $\left(r_{G}\right)$ is chosen to be $\sqrt{2}$. Based on the mesh refinement ratio, the final mesh numbers for each mesh configuration are listed in TABLE II. Moreover, rated velocity and rotation speed are chosen as $11.4 \mathrm{~m} / \mathrm{s}$ and $12.1 \mathrm{rpm}$. As can be seen from the

Fig. 11-13 show the comparison of the unsteady results listed in TABLE III, reasonably small levels of uncertainty are estimated for power and thrust. Uncertainties UG $(1.817 \%$ and $0.874 \%)$ are predicted for power, and $0.137 \%$ and $0.0171 \%$ for thrust, respectively. The difference is so small to ignore. Therefore, we can identify that the mesh method is appropriate for this simulation.

\section{B. CFD results compare with FAST}

The simulation of the operating condition is defined by a wind speed of $8 \mathrm{~m} / \mathrm{s}$ and $11 \mathrm{~m} / \mathrm{s}$ and $\mathrm{rpm}$ of 9.16 and 12.1 , respectively [4]. Three different case conditions (below rated, rated and severe) are selected to simulate and analyse aerodynamic characteristics of FOWT shown in TABLE IV. The platform motion results in regular wave are from FAST calculations. It can be seen from Fig. 10 that the simulation motion can be defined as a simple harmonic platform motion. The pitching and surging motions are given as the following equations: $\quad \theta_{\text {pitch }}=A m p \cdot \sin (2 \pi$. Freq.t $)$ and $\theta_{\text {surge }}=$ Amp. $\sin (2 \pi$. Freq. $t+\varphi)$. The constant coefficient Pitching Amplitude and Surge Amplitude (Amp) are given in TABLE V.
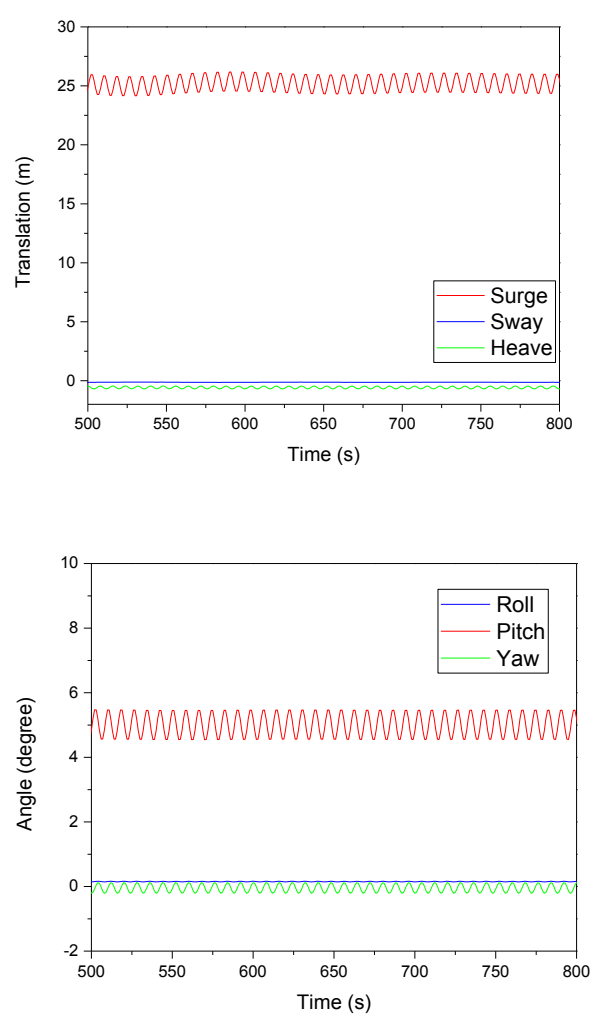

Fig. 10. Severe sea condition at below-rated

aerodynamic power and thrust responses among the CFD and FAST solvers at pitch-surge combined motions at the wind speed of $8 \mathrm{~m} / \mathrm{s}$ and $11.4 \mathrm{~m} / \mathrm{s}$, respectively. The maximum, mean and minimum power and thrust compares with three different methods in pitch and surge combined motions according to the curves are listed in TABLE VI. It is observed from these plots that the power calculated with FAST match well with the CFD results. All the differences are under $15 \%$. What's more, the severe condition makes a difference larger as well. Therefore, 
FAST may not predict aerodynamic performance of FOWT at a complex and severe motion. Moreover, FAST with BEM approach underestimated these values compared to the FAST with GDW, especially in the peak area results. The unsteady CFD can effectively predict the aerodynamic the aerodynamic wake effect better than other numerical approaches. Considering the viscous effect and vortex wake, real blade rotation about a hub centre can account for the flow field interaction. CFD method generates the lowest estimation of aerodynamic power responses. In the power results, CFD has a big difference with BEM than that with GDW while it is revised in the thrust results. The maximum point gets a largest discrepancy which can reach more than $10 \%$.

At the $1 / 4 \mathrm{~T}$, aerodynamic power tends to increase because the additional velocity increases and make the strong interaction between the rotor blades and wake regime. However, at the $4 / 4 \mathrm{~T}$, the aerodynamic power phenomenon is reversed due to the decreasing of the additional velocity. At the 2/4T and 3/4T, weak wake interactions between the rotor blades and its wake. Therefore, the additional velocity contribution and non-axial angle maintain a key role in the aerodynamic performance.
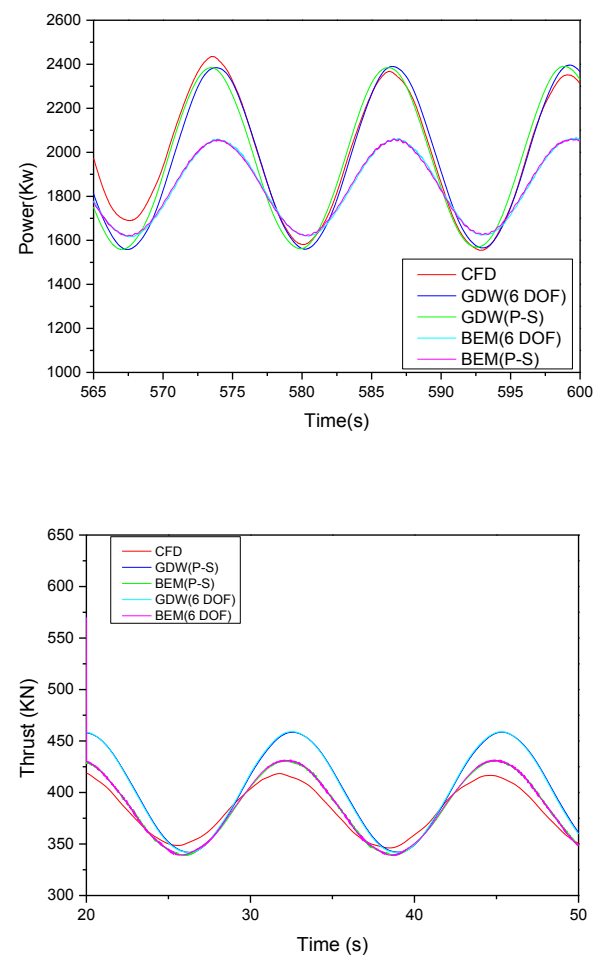

Fig. 11 Power and thrust curve at below-rated condition
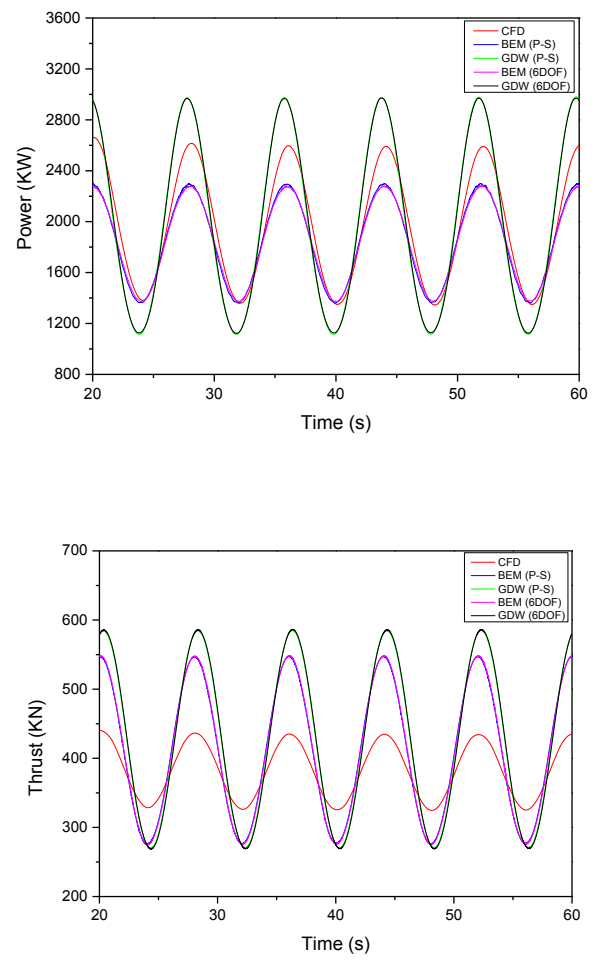

Fig. 12. Power and thrust curve at sever condition
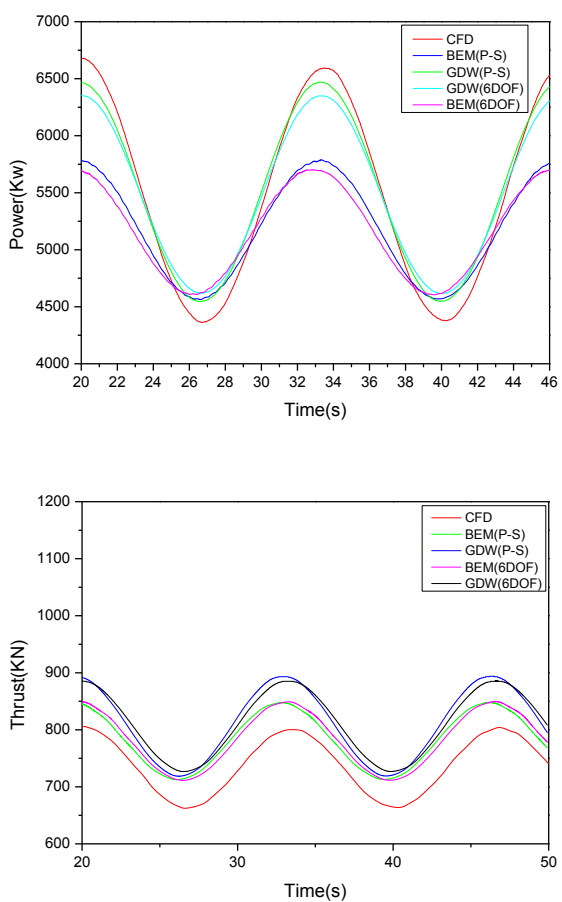

Fig. 13. Power and thrust curve at rated condition 
TABLE I. Three different mesh sizes

\begin{tabular}{|c|c|c|c|}
\hline CFD mesh type & Case 1 & Case 2 & Case 3 \\
\hline Maximum size & $0.03 \mathrm{~m}$ & $0.024 \mathrm{~m}$ & $0.015 \mathrm{~m}$ \\
\hline Minimum size & $0.09 \mathrm{~m}$ & $0.072 \mathrm{~m}$ & $0.045 \mathrm{~m}$ \\
\hline Total number (million) & 9.06 & 17.5 & 27.8 \\
\hline
\end{tabular}

TABLE II. The final cell numbers for each mesh configuration as a result of the mesh convergence study

\begin{tabular}{|l|l|l|l|}
\hline \multirow{2}{*}{ Mesh configuration } & Cell number (million) & Total \\
\cline { 2 - 4 } & Station region & Rotation region & 55.98 \\
\hline Fine & 0.165 & 27.737 & 27.95 \\
\hline Medium & 0.165 & 16.795 & 13.96 \\
\hline Coarse & 0.165 & 2786 & \\
\hline
\end{tabular}

TABLE III. Grid convergence study for Power and Thrust

\begin{tabular}{|c|c|c|c|c|c|c|c|c|c|c|}
\hline \multirow[t]{2}{*}{ Parameter } & \multirow[t]{2}{*}{$r_{G}$} & \multicolumn{3}{|l|}{ Solutions } & \multirow[t]{2}{*}{$\mathbf{R}_{\mathbf{G}}$} & \multirow{2}{*}{$\begin{array}{r}\delta_{G}^{*} \\
\% \mathbf{S}_{1} \\
\end{array}$} & \multirow{2}{*}{$\begin{array}{l}\mathrm{U}_{\mathrm{G}} \\
\% \mathrm{~S}_{1} \\
\end{array}$} & \multirow{2}{*}{$\begin{array}{l}\mathbf{U}_{\mathrm{Gc}} \\
\% \mathrm{~S}_{1} \\
\end{array}$} & \multirow[t]{2}{*}{ GCI } & \multirow[t]{2}{*}{$\mathbf{S}_{\mathbf{c}}$} \\
\hline & & $S 1$ & $S 2$ & $S 3$ & & & & & & \\
\hline Power (KW) & $\sqrt{2}$ & 4719.12 & 4674.65 & 4607.11 & 0.66 & -0.94 & 1.817 & 0.874 & 2.27 & 4719.18 \\
\hline Thrust (KN) & $\sqrt{2}$ & 666.5 & 665.7 & 664.2 & 0.53 & 0.12 & 0.137 & 0.0171 & 0.1715 & 666.50 \\
\hline
\end{tabular}

TABLE IV. Wind and sea state definitions for FAST simulations

\begin{tabular}{|c|c|c|c|c|}
\hline Conditions & $\left.\mathbf{U}_{\infty(\mathbf{~}} \mathbf{m} \mathbf{s}\right)$ & $\mathbf{\Omega}(\mathbf{r p m})$ & $\mathbf{H}_{\mathbf{s}}(\mathbf{m})$ & $\mathbf{T}_{\mathbf{p}}(\mathbf{s})$ \\
\hline Below-rated & 8 & 9.16 & 1.83 & 12.72 \\
\hline Severe sea condition & 8 & 9.16 & 5 & 8 \\
\hline Rated & 11.4 & 12.10 & 2.54 & 13.35 \\
\hline
\end{tabular}

TABLE V. Output from FAST

\begin{tabular}{|c|c|c|c|}
\hline Conditions & $\begin{array}{c}\text { Platform } \\
\text { Pitching } \\
\text { Amplitude } \\
\text { (degree) }\end{array}$ & $\begin{array}{c}\text { Platform } \\
\text { Mean Pitch } \\
\text { Angle (degree) }\end{array}$ & $\begin{array}{c}\text { Platform } \\
\text { Surge } \\
\text { Amplitude } \\
\text { (m) }\end{array}$ \\
\hline Below-rated & 0.336 & 2.5 & 0.7 \\
\hline $\begin{array}{c}\text { Severe sea } \\
\text { condition }\end{array}$ & 0.36 & 5 & 0.65 \\
\hline Rated & 0.49 & 5 & 1.14 \\
\hline
\end{tabular}

TABLE VI. Power and thrust comparison with different methods at P-S condition

\begin{tabular}{|c|c|c|c|c|c|c|c|c|c|c|}
\hline \multicolumn{11}{|c|}{ P-S Power $(K W)$} \\
\hline & \multirow[t]{2}{*}{ Condition } & \multicolumn{3}{|c|}{ Maximum } & \multicolumn{3}{|c|}{ Mean } & \multicolumn{3}{|c|}{ Minimum } \\
\hline & & $C F D$ & BEM & $G D W$ & $C F D$ & BEM & $G D W$ & $C F D$ & BEM & $G D W$ \\
\hline 1 & Below & 2366 & 2061 & 2389 & 1979 & 1836 & 1950 & 1556 & 1625 & 1566 \\
\hline 2 & Severe & 2560 & 2281 & 2971 & 1997 & 1822 & 2013 & 1348 & 1374 & 1129 \\
\hline \multirow[t]{3}{*}{3} & Rated & 6591 & 5702 & 6349 & 5452 & 5155 & 5463 & 4384 & 4607 & 4618 \\
\hline & & \multicolumn{3}{|c|}{ Below-rated } & \multicolumn{3}{|c|}{ Severe sea condition } & \multicolumn{3}{|c|}{ Rated } \\
\hline & & $\operatorname{Max}$ & Mean & Min & $\operatorname{Max}$ & Mean & Min & $\operatorname{Max}$ & Mean & Min \\
\hline \multicolumn{2}{|c|}{$\begin{array}{l}\text { Difference }(\%) \\
\text { (CFD vs BEM) }\end{array}$} & 12.9 & 7.2 & 4.4 & 10.9 & 8.8 & 1.9 & 13.5 & 5.5 & 5.1 \\
\hline \multicolumn{2}{|c|}{$\begin{array}{l}\text { Difference }(\%) \\
(\mathrm{CFD} \text { vs GDW) }\end{array}$} & 1.0 & 1.5 & 0.6 & 16.0 & 0.8 & 15.7 & 3.7 & 0.2 & 5.3 \\
\hline \multicolumn{11}{|c|}{ P-S Thrust (KN) } \\
\hline & \multirow[t]{2}{*}{ Condition } & \multicolumn{3}{|c|}{ Maximum } & \multicolumn{3}{|c|}{ Mean } & \multicolumn{3}{|c|}{ Minimum } \\
\hline & & $C F D$ & BEM & $G D W$ & $C F D$ & BEM & $G D W$ & $C F D$ & BEM & $G D W$ \\
\hline 1 & Below & 417 & 431 & 459 & 379 & 382 & 398 & 346 & 339 & 342 \\
\hline 2 & Severe & 435 & 548 & 586 & 379 & 412 & 427 & 326 & 276 & 269 \\
\hline \multirow[t]{3}{*}{3} & Rated & 800 & 849 & 885 & 735 & 784 & 802 & 664 & 712 & 727 \\
\hline & & \multicolumn{3}{|c|}{ Below-rated } & \multicolumn{3}{|c|}{ Severe sea condition } & \multicolumn{3}{|c|}{ Rated } \\
\hline & & $\operatorname{Max}$ & Mean & Min & $\operatorname{Max}$ & Mean & Min & $\operatorname{Max}$ & Mean & Min \\
\hline \multicolumn{2}{|c|}{$\begin{array}{l}\text { Difference }(\%) \\
\text { (CFD vs BEM) }\end{array}$} & 3.4 & 0.8 & 2.0 & 26.0 & 8.7 & 15.3 & 6.1 & 6.7 & 7.2 \\
\hline \multicolumn{2}{|c|}{$\begin{array}{l}\text { Difference (\%) } \\
\text { (CFD vs GDW) }\end{array}$} & 10.1 & 5.0 & 1.2 & 34.7 & 12.7 & 17.5 & 10.6 & 9.1 & 9.5 \\
\hline
\end{tabular}




\section{BEMT modified using 2D CFD Data}

Lift (CL) and drag (CD) coefficients by 2D CFD calculations are utilized into FAST to obtain power and thrust. 2D airfoil data based on CFD computations are shown in Fig. 14. The thrust and power coefficient of severe condition computed using BEMT is given in Fig. 15.
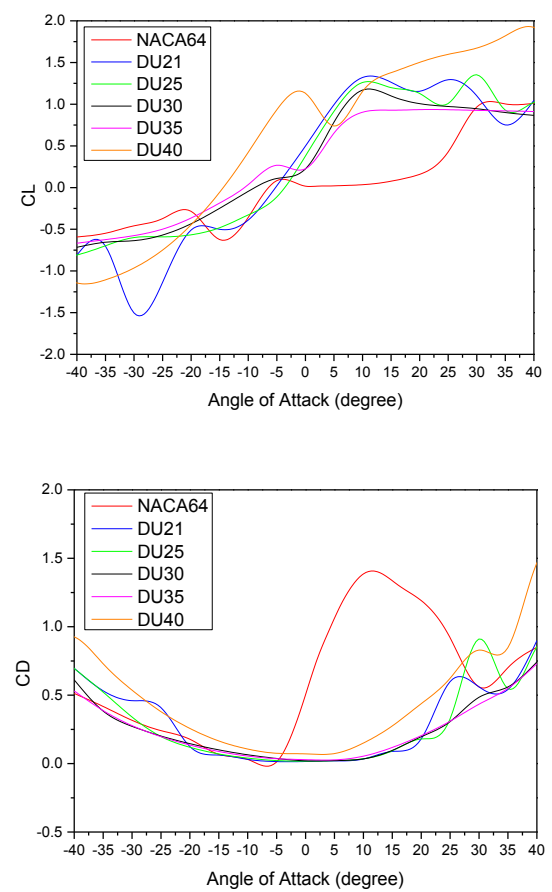

Fig. 14. 2D airfoil data based on CFD
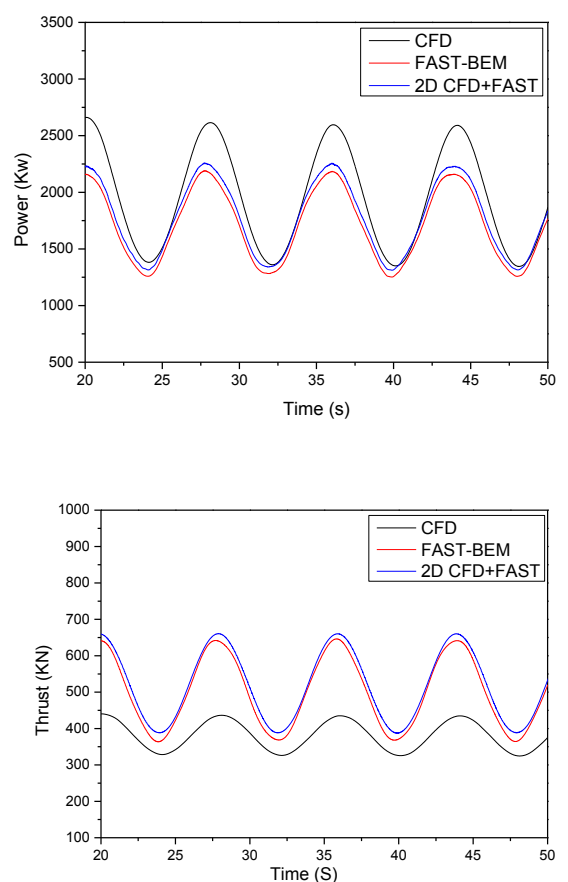

Fig. 15. Power and thrust comparison
Although 2D CFD results are expected to give better estimates of the flow features and aerodynamic coefficients, their effect on the BEMT-based wind turbine performance predictions is not satisfactory. A straightforward approach based on 2D calculations does not give realistic loads on the rotor. The overall effect of using CFD-based input data on power and thrust is small. It is probable that the unsatisfactory BEMT-based performance predictions are due to the radial velocity components as observed in the 3D RANS results. These velocity components are not considered within BEMT using any $2 \mathrm{D}$ input data.

\section{BEMT modified using 2D Airfoil Data from $3 D C F D$ Computations}

Owing to the highly three-dimensional flow, sectional aerofoil characteristics will deviate from 2D aerofoil characteristics, especially at the inner part of the blade and near the blade tip. Therefore, airfoil data from 3D CFD calculation were fed into FAST.

Lift and drag force can be calculated using the normal and tangential components of force which can be found in the CFD simulation results. To do this, the angle of attack has to be established by calculating the relative inflow angle to the blade. The approach to get the angle of attack is prescribed in session 2 .

Overall, extract 2D aerodynamic coefficient from 3D CFD calculation is described in Fig. 16. Based on the input data which are generated using the proposed 3D CFD based method, BEMT performance predictions were done. In Fig. 17, power is plotted.

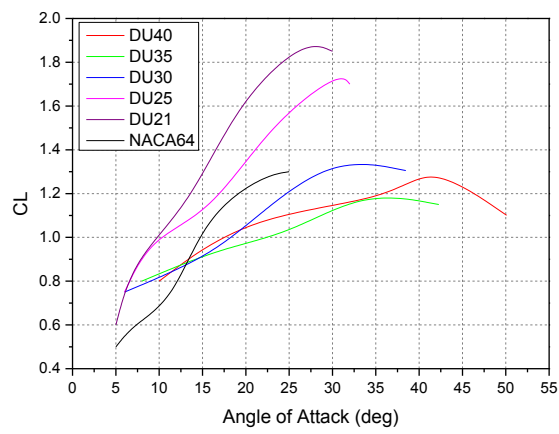

Fig. 16. 2D airfoil data from 3D CFD

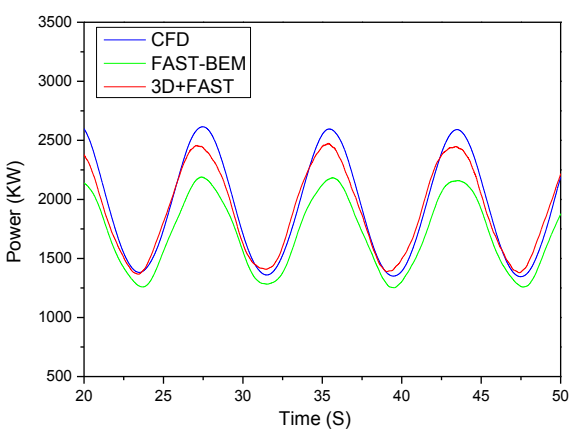

Fig. 17. Power comparison 
Results based on 3D CFD calculations come close to the full CFD results. The predictions based on the post-processed 3D CFD data are in good overall agreement with the full 3D CFD computations. Especially, the minimum values are almost identical.

\section{CONCLUSION}

Three different case conditions (below rated, rated and severe) are selected to simulate and analyse aerodynamic characteristics of FOWT in this chapter. The pitching and surging motions are given as the following equations: $\theta_{\text {pitch }}=$ Amp. $\sin (2 \pi$.Freq.t $)$ and $\theta_{\text {surge }}=A m p \cdot \sin (2 \pi$. Freq. $t+$ $\varphi)$.

First, when compared with BEM and GDW solvers, power and thrust match well with CFD results. All the discrepancies are smaller than $15 \%$. Pitch and surge combined motions reach the maximum difference. Moreover, BEM approach underestimates these values compared with GDW, while CFD method produces the lowest estimation.

Moreover, this paper uses a link between RANS and BEMT calculations of FOWT at severe condition. 2D and 3D RANS results are as input for BEMT computations. Several results are detected as follows:

-Flow around turbine blade more 2D for full scale

-Full scale results more appropriate for this approach

-Similar results for CFD 3D and RANS-BEMT

-RANS-BEMT approach relies on RANS and BEMT results

-Differences are acceptable

Overall, the use of purely 2D data from 2D CFD RANS computations does however not result in the desired improvement due to the highly $3 \mathrm{D}$ character of the flow which is not considered the conventional BEMT. However, the 3D CFD+FAST approach is shown to be successful and can therefore be extremely useful for future FOWT performance prediction. RANS-BEMT coupled approach is an option to be taken into account.

\section{REFERENCES}

[1] L. J. Gordon, "Challenges in modeling the unsteady aerodynamics of wind turbines", $21^{\text {st }}$ ASME Wind Energy Symposium and the $40^{\text {th }}$ AIAA Aerospace Sciences Meeting, Reno, NV, AIAA 2002-0037.

[2] J. Jonkman, "Dynamics modeling and loads analysis of an offshore floating wind turbine", Technical Report, NREL/TP-500-41958, November, 2007.

[3] Minu Jeon, Seungmin Lee and Soogab Lee, (2014), Unsteady Aerodynamics of Offshore Floating Wind Turbines in Platform Pitching Motion using Vortex Lattice Method, Renewable Energy, 2014, vol. 65, issue C, pages 207-212.

[4] T. Tran, D. Kim, J. Song, "Computational fluid dynamic analysis of a floating offshore wind turbine experiencing platform pitching motion", Energies 2014, 7, 5011-5026; doi:10.3390/en7085011.

[5] D. Matha, M. Schlipf, A. Cordle, R. Pereira, J. Jonkman, "Challenges in simulation of aerodynamics, hydrodynamics, and mooring-line dynamics of floating offshore wind turbines", Presented at the $21^{\text {st }}$ Offshore and Polar Engineering Conference, Maui, Hawaii , June 19-24, 2011.

[6] A. Bahuguni, K. Sivalingam, P. Davies, Johan Gullman-Strand , V. T. Nguyen, "Implementation of computational methods to obtain accurate induction factors for offshore wind turbines", the ASME $201433^{\text {rd }}$
International Conference on Ocean, Offshore and Arctic Engineering, OMAE2014, June 8-13, 2014, San Francisco, California, USA, OMAE2014-23992.

[7] T. Sebastian, M. Lackner, "Offshore floating wind turbines - an aerodynamic perspective", 49 ${ }^{\text {th }}$ AIAA Aerospace Sciences Meeting including the New Horizons Forum and Aerospace Exposition 4-7 January, 2011 Orlando, Florida AIAA 2011-720 (doi: 10.2514/6.2011720).

[8] T. Sebastian, M. Lackner, "A comparison of first-order aerodynamic analysis methods for floating wind turbines", 48 ${ }^{\text {th }}$ AIAA Aerospace Sciences Meeting Including the New Horizons Forum and Aerospace Exposition 4-7 January 2011 Orlando, Florida AIAA 2010-998 (doi: 10.2514/6.2010-998).

[9] A. Garrel, "Development of a wind turbine aerodynamics simulation module", Technical Report ECN-C-03-079, ECN, 2003.

[10] S. Gueydon, G. Venet, G. Fernandes, "Influence of the rotor characterization on the motion of a floating wind turbine", Proceedings of the ASME $201534^{\text {th }}$ International Conference on Ocean, Offshore and Arctic Engineering, OMAE2015, May 31-June 5, 2015, St. John's, Newfoundland, Canada.

[11] E.-J. de Ridder, W. Otto, G.-J. Zondervan., F. Huijs, and G. Vaz, "Development of a scaled-down floating wind turbine for offshore basin testing", Proceedings of OMAE2014 $33^{\text {rd }}$ International Conference on Offshore Mechanics and Arctic Engineering, 8-13 June 2014, San Francisco, California, USA.

[12] G. Fernandes, M. Make, S. Gueydon and G. Vaz, "Sensitivity to aerodynamic forces for the accurate modelling of floating offshore wind turbines", In $1^{\text {st }}$ International Conference on Renewable Energies Offshore, 24-26 Nov 2014, Lisbon, Portugal, RENEW2014.

[13] M. Jason Jonkman, L. Buhl Jr. Marshall, "FAST user's guide”, Technical Report NREL/EL-500-38230, August, 2005.

[14] David J. Laino, A. Craig Hansen, Jeff E. Minnema, "Validation of the AeroDyn subroutines using nrel unsteady aerodynamics experiment data, wind energy", Volume 5, Issue 2-3, April - September 2002, Pages 227 244.

[15] P.J. Moriarty, A.C. Hansen, "AeroDyn theory manual", NREL/TP-50036881, January, 2005.

[16] T. Burton, "Wind energy handbook", John Wiley \& Sons Ltd.: Chichester, UK, 2011.

[17] J. Jonkman, "Dynamics modelling and loads analysis of an offshore floating wind turbine", Technical Report, NREL/TP-500-41958, November, 2007.

[18] A. N. Robertson, J. M. Jonkman, A. J. Goupee, A. J. Coulling, I. Prowell, J. Browning, "Summary of conclusions and recommendations drawn from the deepcwind scaled floating offshore wind system test campaign", In: Conference: ASME $201332^{\text {nd }}$ International Conference on Ocean, Offshore and Arctic Engineering, 2013.

[19] F. Bertagnolio, N. Sorensen, J. Johansen and P. Fuglsang, "Wind turbine airfoil catalogue", Riso National Laboratory, Roskilde, Denmark, August , 2001, Riso-R-1280.

[20] S. Guntur, N. Sørensen, "Evaluation of several methods of determining the angle of attack on wind turbine blades", Journal of Physics: Conference Series (Online), Vol. 555, 012045, 2014.

[21] J. F. Manwell, J. G. McGowan, and A. L. Rogers, "Wind energy explained -theory, design and application", John Wiley \& Sons Ltd, 2003.

[22] M. Hansen, N. Sorensen, J. Sorensen, and J. Mikkelsen, "Extraction of Lift, Drag and Angle of Attack from Computed 3D Viscous Flow around a Rotating Blade", Proc. of the European Wind Energy Conference (Dublin), 2003, pp 499-501.

[23] J. Jonkman, S. Butterfield, W. Musial, and G. Scott, "Definition of a 5MW reference wind turbine for offshore system development", Technical Report, NREL/TP-500-38060, February, 2009.

[24] ITTC, "Uncertainty analysis in CFD verification and validation methodology and procedures", ITTC - Recommended Procedures and Guidelines, 7.5-03 -01-01, 2008.

[25] R. Wilson, and F. Stern, "Verification and validation for RANS simulation of a naval surface combatant, standards for CFD in the 
aerospace industry”, 2002 AIAA Aerospace Sciences Meeting, Reno, Nevada, 14-17 January, 2002.

[26] R. Wilson, J. Shao, and F. Stern, "Discussion: criticism of the correction factor verification method”, ASME J. Fluids Eng., Vol. 126, July, 2004.

[27] T. Xing, F. Stern, "Factors of safety for Richardson extrapolation", J. Fluids Eng. 132 (6), 2010
[28] P. J. Roache, "Verification and validation in computational science and engineering", Hermosa Publishers, Albuquerque, New Mexico, 1998.

[29] F.Stren F. Stern, R. Wilson, and J. Shao, "Quantitative V\&V of CFD simulations and certification of CFD codes", Int. J. Numer. Methods Fluids, 2006, pp 1335-1355. 